\title{
SISTEM PENGAMANAN PINTU RUMAH DENGAN RFID BERBASIS WIRELESS ESP8266
}

\author{
Ryan Laksmana Singgeta, ST., MSc ${ }^{1}$, Pinrolinvic D.K. Manembu, S.T., M.T., ${ }^{2}$ Mark D. Rembet ${ }^{3}$ \\ ${ }^{1}$ Program Studi Teknik Elektro, Fakultas Teknik, Universitas Katolik De La Salle Manado \\ Kairagi I Kombos Manado, Sulawesi Utara \\ Telp. (0431) 871972 \\ ${ }^{2}$ Jurusan Teknik Informatika, Fakultas Teknik, Universitas Sam Ratulangi \\ Kampus UNSRAT, Bahu \\ Telp. (0431) 863886 \\ ${ }^{3}$ Program Studi Teknik Informatika, Fakultas Teknik, Universitas Katolik De La Salle Manado \\ Kairagi I Kombos Manado, Sulawesi Utara \\ Telp. (0431) 871972
}

E-mail: rsinggeta@unikadelasalle.ac.id,pmanembu@unsrat.ac.id,markrembet@gmail.com

\begin{abstract}
ABSTRAKS
Suatu perangkat sistem keamanan pintu rumah sedang dikembangkan untuk menjaga asset dan privasi yang dimiliki. Pengembangan peralatan keamanan ini harus diteliti dan diuji dengan baik sehingga memiliki tahapan yang benar. Pemanfaatan RFID telah dilakukan pada penelitian sebelumnya. Namun sistem tersebut yang telah dirancang masih memiliki banyak kendala apabila jumlah pintu yang akan dipasangkan terlalu banyak. Pada paper ini telah dilakukan pengembangan pada penelitian sebelumnya dalam hal fleksibilitas sistem. Media komunikasi kabel sebelumnya digantikan dengan media wireless yang lebih efisien dan efektif. Raspberry Pi adalah suatu Single Board Computer (SBC) yang digunakan penulis sebagai pengganti komputer desktop sebagai webserver pada sistem keamanan rumah. Performansi dari ESP8266 WiFi dan SBC sebagai server dapat berjalan dengan baik dimana request dari client dapat di handle dengan waktu respon sekitar 2000 milidetik. Selain itu, dengan menggunakan perangkat ESP8266, penggunaan kabel dapat diminimalisir serta proses pemasangan sensor dapat lebih mudah dan efektif.
\end{abstract}

\section{Kata Kunci: ESP82660, Radio Frequency Identification, Raspberry Pi}

\section{PENDAHULUAN}

\subsection{Latar Belakang}

Sistem pengamanan pintu rumah menjadi isu penting pada zaman sekarang ini. Isu keamanan dalam rumah merupakan sesuatu hal penting dan sering dibicarakan dilingkungan sekitar. Sistem keamanan rumah yang kurang ketat dapat mengundang hal - hal yang tidak diinginkan seperti pencurian dan sebagainya. Oleh karena itu dibutuhkan suatu perangkat sistem keamanan pintu untuk keamanan yang dapat menjaga keamanan setiap waktu bahkan melindungi asset dan privasi yang dimiliki. Pada umumnya pengaman pintu pada rumah yang digunakan masyarakat masih menggunakan kunci biasa. Dalam memenuhi kriteria di atas, maka pengembangan peralatan keamanan ini terus diteliti dan diuji dengan baik. Sebagai pengganti kunci pintu manual pemanfaatan RFID telah dilakukan pada penelitian sebelumnya. Sistem Radio Frequency Identification (RFID) adalah sebuah teknologi yang dapat mendeteksi identitas pengguna dimana proses ini terbilang unik karena tidak harus bersentuhan langsung dengan RFID Reader.

Kemajuan teknologi radio frequency (RF) semakin meningkat dan banyak digunakan di berbagai macam jenis aplikasi, misalnya pada televisi, radio, telepon selular, radar, dan automatic identification system (Suryadiputra, 2010). Radio frequency identification (RFID) bekerja menggunakan radio frequency signals untuk kemudian menentukan identitas dari sesuatu secara otomatis. RFID biasa digunakan untuk: electronic toll collection (ETC), railway car identification and tracking, intermodal container identification, asset identification and tracking, item management for retail, health care, and logistics application, access control, animal identification, fuel dispensing loyalty programs, and automobile immobilizing (security). Beberapa penelitian telah dilakukan dalam mengembangkan teknologi RFID. Pada paper penulis (Charles P. M, 2010), sistem pembayaran biaya parkir dirancang secara otomatis menggunakan RFID (Radio Frequency Identification). ID yang ada di dalam tag akan dibaca oleh RFID reader. ID tersebut diolah di database untuk mengetahui identitas pemilik ID ketika masuk ke tempat parkir maupun akan keluar dari tempat parkir. Sistem ini sangat membantu pengguna layanan parkir agar tidak antri ketika masuk maupun keluar tempat parkir. Selain itu sistem tersebut memberikan kemudahan bagi pengelola parkir dalam penyebaran informasi menjadi lebih aman, cepat dan akurat. Pada paper dengan penulis (Beny. N, dkk, 2015), RFID digunakan sebagai sistem 
identifikasi lantai pada miniatur lift berbasis arduino. Pada penggunaan lift saat itu masih menggunakan tombol sebagai penanda lantai, dimana setiap orang yang masuk ke dalam lift dapat menekan tombol lantai yang ingin mereka tuju. Setiap penghuni apartemen memiliki kartu RFID yang berisikan data lantai kamar mereka masing-masing. Hasil pengujian yang didapatkan, dengan menggunakan sistem indentifikasi kartu RFID, lift hanya bergerak ke lantai yang sesuai dengan kartu RFID tersebut sehingga para penghuni apartement dapat langsung menuju ke kamarnya masing-masing tanpa perlu menekan tombol. Adapun pada paper penulis (Eko B. S, \& Bobi. K, 2015), RFID digunakan untuk sistem absensi kehadiran perkuliahan. Absensi perkuliahan adalah salah satu permasalahan yang ada pada lingkungan akademik. Banyaknya suatu data absensi setiap matakuliah untuk setiap mahasiswa, menjadikan proses absensi menjadi tidak efektif dan tidak efisien. Dengan dirancang sistem absensi kehadiran perkuliahan di Universitas Komputer Indonesia (UNIKOM) berbasis teknologi Radio Frequency Identification (RFID), proses perkuliahan akademik di UNIKOM bisa berjalan dengan efektif.

Pada paper dengan penulis (Pinrolinvic M., 2015), merupakan penelitian sebelumnya dimana sistem pengamanan pintu menggunakan RFID (Radio Frequency Identification) sensor dirancang yang mudah digunakan pada pintu rumah, maupun indekos. Paper tersebut menggunakan beberapa perangkat keras seperti arduino uno, RFID-MFRC-522, relay dan Ethernet Shield. Modul Ethernet shield digunakan untuk mengkoneksikan Arduino dengan internet atau jaringan dengan menggunakan kabel (Wired). Pada paper tersebut pintu dibagi ke dalam 2 kategori yaitu pintu utama dan pintu kamar, jadi setiap pengguna dapat mengakses pintu utama dan untuk pintu kamar setiap pengguna hanya bisa mengakses satu pintu yaitu pintu kamarnya sendiri. Perangkat lunak yang didesain akan melakukan monitoring semua pintu yang ada karna di asumsikan pintu-pintu tersebut merupakan pintu pada rumah-rumah kos, perangkat lunak juga dapat mendeteksi waktu jatuh tempo atau masa aktif kartu, sehingga dapat dijadikan sebagai alat monitor pembayaran sewa kamar. Penerapan sistem RFID yang melibatkan banyak ruangan atau kamar pada penelitian tersebut, memerlukan penanganan yang serius terutama untuk pengkabelan, sebab media komunikasi antara RFID sensor dan server penyedia data masih menggunakan kabel-kabel LAN, selain itu pula kebutuhan sebuah computer untuk bertindak sebagai server di rasa kurang efisien dalam pengimplementaasian sistem ini dilokasi rumah kos ataupun gedung yang memiliki ruangan banyak.

Pada paper ini telah dilakukan pengembangan pada penelitian sebelumnya dalam hal fleksibilitas sistem. Media komunikasi kabel sebelumnya digantikan dengan media wireless yang lebih efisien dan efektif. Raspberry Pi adalah suatu Single Board Computer (SBC) yang digunakan penulis sebagai pengganti komputer desktop sebagai webserver pada sistem keamanan rumah. Web database digunakan sebagai tempat menyimpan informasi dari pengguna dan kemudian dapat diakses dengan mudah.

\subsection{Rumusan Masalah}

Bagaimana mengembangkan sistem pengamanan pintu rumah dengan RFID berbasis wireless ESP8266?

\subsection{Tujuan}

Mengembangkan sistem pengamanan pintu rumah dengan RFID dalam hal fleksibilitas sistem. Dimana Ethernet Shield digantikan dengan teknologi wireless ESP8266 yang lebih efektif dan efisien.

\section{$1.4 \quad$ Tinjauan Pustaka}

\section{Jaringan Komputer}

Perkembangan kebutuhan pengolahan data dan informasi, didalam sebuah perusahaan dibutuhkan beberapa komputer yang digunakan oleh banyak orang yang bekerja dalam sebuah tim. Pertukaran data dan informasi, maka komputer - komputer yang digunakanakan terhubung satu dengan yang lainnya. Kumpulan komputer yang saling terhubung disebut jaringan komputer (Madcoms 2010). Jaringan client server menghubungkan komputer server dengan komputer klien / workstation. Komputer server adalah komputer yang menyediakan fasilitas bagi komputer-kompute klien / workstation yang terhubung dalam jaringan. komputer server pada sebuah jaringan tipe client server disebut dengan Dedicated server, karena komputer yang digunakan hanya sebagai penyedia fasilitas untuk komputer klien / workstation. Komputer server tidak dapat berperan sebagai komputer klien/workstation (Madcoms 2010). Keunggulan tipe client server adalah:

1. Terdapat administrator jaringan yang mengelola sistem keamanan dan administrasi jaringan sehingga lebih terkontrol.

2. Komputer server difungsikan sebagai pusat data, klien dapat mengakses data dari komputer klien manapun.

3. Pengaksesan data lebih tinggi karena penyediaan dan pengelolaan fasilitas jaringan dilakukan oleh komputer server. 
4. Pada tipe jaringan client server, sistem backup data lebih baik, karena backup data dapat dilakukan terpusat di komputer server.

\section{Topologi Star}

Topologi star adalah konfigurasi beberapa komputer yang terkoneksi melalui sebuah switch/hub dan kabel UTP. Topologi ini merupakan topologi yang paling populer diaplikasikan. Pada topologi ini walaupun kabel UTP sebagai pilihan utama, tetapi dapat juga menggunakan kabel fiber optic. Bentuk topologi ini diperlihatkan pada gambar dibawah ini (Aryanto 2010):

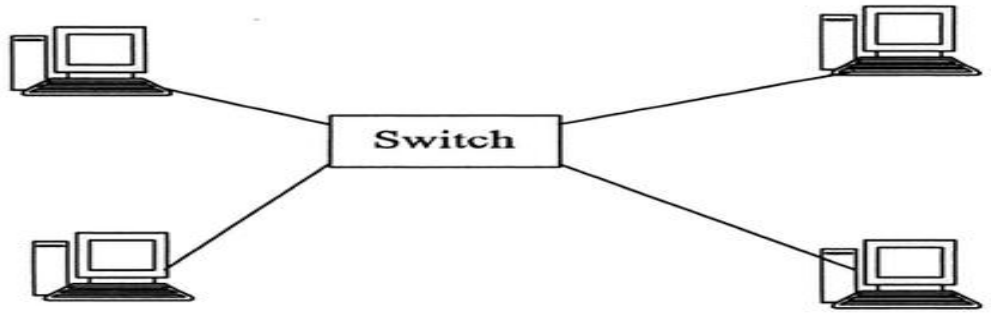

Gambar 1. Bentuk Topologi Star (Aryanto 2010)

\section{RFID (Radio Frequency Identification System)}

Radio Frequency Identification (RFID) adalah teknologi untuk mengidentifkasi dan mengendalikan data dari jarak jauh menggunakan transmisi gelombang radio. RFID menggunakan sarana transponder atau RFID tag untuk menyimpan dan mengambil data dari jarak jauh. RFID tag mirip denganp penggunaan barcode yang melekat pada sebuah objek yang menyimpan identifikasi data obyek. Antenna adalah salah satu komponen penting pada RFID tag yang digunakan untuk mengirim dan menangkap sinyal informasi yang dipancarkanan antenna menggunakan gelombang radio(Yuwono 2014). Berdasarkan definisi menurut (Maryono, 2005) identifikasi dengan frekuensi radio adalah teknologi untuk mengidentifikasi seseorang atau objek benda menggunakan transmisi frekuensi radio, khususnya $125 \mathrm{kHz}, 13.65 \mathrm{Mhz}$ atau $800-900 \mathrm{MHz}$. RFID menggunakan komunikasi gelombang radio untuk secara unik mengidentifikasi objek atau seseorang. Terdapat beberapa pengertian RFID menurut (Maryono, 2005) yaitu :

a. RFID (Radio Frequency Identification) adalah sebuah metode identifikasi dengan menggunakan sarana yang disebut label RFID atau transponder (tag) untuk menyimpan dan mengambil data jarak jauh.

b. Label atau transponder (tag) adalah sebuah benda yang bisa dipasang atau dimasukkan di dalam sebuah produk, hewan atau bahkan manusia dengan tujuan untuk identifikasi menggunakan gelombang radio. Label RFID terdiri atas mikrochip silikon dan antenna.

Suatu sistem RFID secara utuh terdiri atas 3 (tiga) komponen:

a. Tag RFID, dapat berupa stiker, kertas atau plastik dengan beragam ukuran (gambar 2). Di dalam setiap tag ini terdapat chip yang mampu menyimpan sejumlah informasi tertentu. RFID Tag berfungsi sebagai transponder (transmitter dan responder) yang berisikan data dengan menggunakan frekuensi $125 \mathrm{KHz}$.

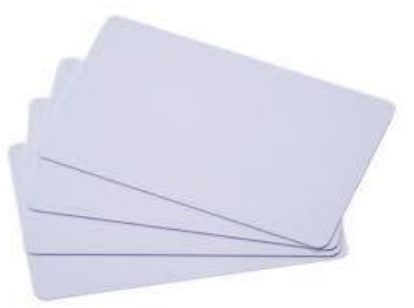

\section{Gambar 2. RFID Tag}

b. Terminal Reader RFID, terdiri atas RFID reader dan antenna yang akan mempengaruhi jarak optimal identifikasi. Terminal RFID akan membaca atau mengubah informasi yang tersimpan di dalam tag melalui frekuensi radio. Terminal RFID terhubung langsung dengan sistem Host 
c. Komputer. Salah satu jenis terminal reader RFID adalah MFRC522 gambar 3. MFRC522 beroperasi pada frekuensi 13.56 MHz dengan konsumsi arus 10-13 mA / DC 3.3 Volt.

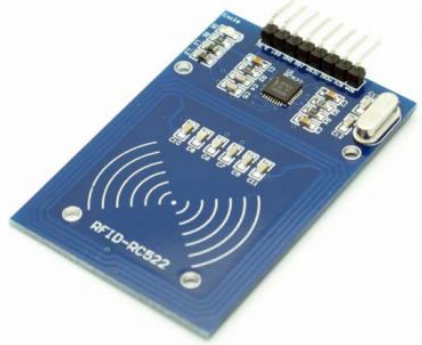

\section{Gambar 3. RFID Reader MFRC522}

Cara kerja dapat diterangkan sebagai berikut (Doni S. dkk, 2010): Label tag RFID yang tidak memiliki baterai, antenna yang berfungsi sebagai pencatu sumber daya dengan memanfaatkan medan magnet dari pembaca (reader) dan memodulasi medan magnet. Kemudian digunakan kembali untuk mengirimkan data yang ada dalam label tag RFID. Data yang diterima reader diteruskan ke database host computer. Reader mengirim gelombang elektromagnet, yang kemudian diterima oleh antenna pada label RFID. Label RFID mengirim data biasanya berupa nomor serial yang tersimpan dalam label, dengan mengirim kembali gelombang radio ke reader. Informasi dikirim ke dan di baca dari label RFID oleh reader menggunakan gelombang radio. Dalam sistem yang paling umum yaitu sistem pasif, reader memancarkan energi gelombang radio yang membangkitkan label RFID dan menyediakan energi agar beroperasi. Sedangkan sistem aktif, baterai dalam label digunakan untuk memperoleh jangkauan operasi label RFID yang efektif, dan fitur tambahan penginderaan suhu. Data yang diperoleh atau dikumpulkan dari label RFID kemudian dilewatkan atau dikirim melalui jaringan komunikasi dengan kabel atau tanpa kabel ke sistem komputer. Antenna akan mengirimkan melalui sinyal frekuensi radio dalam jarak yang relatif dekat. Dalam proses transmisi tersebut terjadi 2 (dua) hal:

a. Antenna melakukan komunikasi dengan transponder, dan

b. Antenna memberikan energi kepada tag untuk berkomunikasi (untuk tag yang sifatnya pasif) Ini adalah kunci dalam teknologi RFID. Sebuah tag pasif yang tidak perlu power seperti baterai sehingga dapat digunakan dalam waktu yang sangat lama. Antenna bisa dipasang secara permanen (walau saat ini tersedia juga yang portable) Bentuknya pun beragam sekarang sesuai dengan keinginan kita. Pada saat tag melewati wilayah sebaran antenna, alat ini kemudian mendeteksi wilayah scanning. Selanjutnya setelah terdeteksi maka chip yang ada di tag akan "terjaga" untuk mengirimkan informasi kepada antenna.

\subsection{Metodologi Penelitian}

Penelitian ini dilakukan dengan beberapa tahapan, sebagain besar pengerjaan penelitian ini dilakukan di laboratorium dan juga ada beberapa kunjungan ke lapangan untuk mendapatkan informasi tentang bagaimna hambaatan dan kendala dalam pengelolaan rumah tempat kos, mulai dari keamaan pintu dan sistem pembayarannya.

Tahapan yang ada meliputi persiapan berupa studi literature, penetuan tujuan dan batasan penelitian, kemudian ke tahap analisis, yaitu dilakukan analisis kebutuhan apa saja yang di perlukan untuk membangun sistem ini, termasuk didalamnya ada proses pengidentifikasian sistem yang akan dibangun. Berdasarkan teori, suatu system memiliki tiga elemen pokok, yaitu masukan (input), proses (process) dan keluaran (output). Tahap selanjutnya perancangan yang akan dikonsentrasikan kepada solusi efektif untuk komunikasi data, dan alternative web server skala kecil. Pada tahap Implementasi dilakukan implementasi sistem yang telah dirancang pada sebuah miniature sederhana. Selanjtnya tahap evaluasi yaitu dengan melakukan pengujian pada peralatan yang sudah dibuat, juga akan melihat kinerja dari proses pengiriman data secara wireless anatra sensor dan web server serta performa dari aplikasi yang dibuat, setelah menggunakan wireless system 


\section{HASIL DAN PEMBAHASAN}

Penelitian ini dilakukan untuk meningkatkan kinerja system yang sudah ada sebelumnya dengan 2 tahapan yaitu pertama efisiensi media komunikasi data dengan menggunakan media wireless. Kedua efisiensi bagian web server dengan menggunakan raspberry sebagai computer mungil yang akan bertindak sebagai server.

\subsection{Media komunikasi wireless}

Pada bagian ini akan didiskusikan tentang solusi dengan menggunakan perangkat wireless sebagai pengganti media kabel dalam komunikasi data. Salah satu alaternatif adalah dengan menggunakan perangkat ESP 8266 sebagai komponen utama pada solusi wireless ini. Pemilihan perangkat ini karena kelebihannya yaitu memiliki harga yang tergolong murah, kemudian secara spesifikasi perangkat ini memiliki fitur yang cukup untuk keperluan pada penelitian ini, seperti

1. Kemampuan IP networking, yang memungkinkan perangkat ini dapat mengakses atau mengendalikan via Internet

2. Serial WiFi SoC (single on Chip) dengan onboard USB to TTL. Untuk Wireless standar yang digunakan adalah IEEE $802.11 \mathrm{~b} / \mathrm{g} / \mathrm{n}$

3. Memiliki CPU 32 bit Tensilica Xtensa LX106 dengan kecepatan 80 Mhz,

4. Memiliki RAM instruksi $64 \mathrm{KiB}$ dan RAM data $96 \mathrm{KiB}$.

5. Memiliki kemampuan berperan sebagai client ataun server.

6. Memiliki beberapa jenis I/O untuk komunikasi data seperti :GPIO, SPI, I2C, I2S, dan ADC

7. Hemat daya karna memiliki fitur deep sleep

8. Pemrograman via, Python, Arduino IDE, LUA

Secara lengkap fitur dari esp8266 dapat dilihat pada gambar 4 dibawah ini.

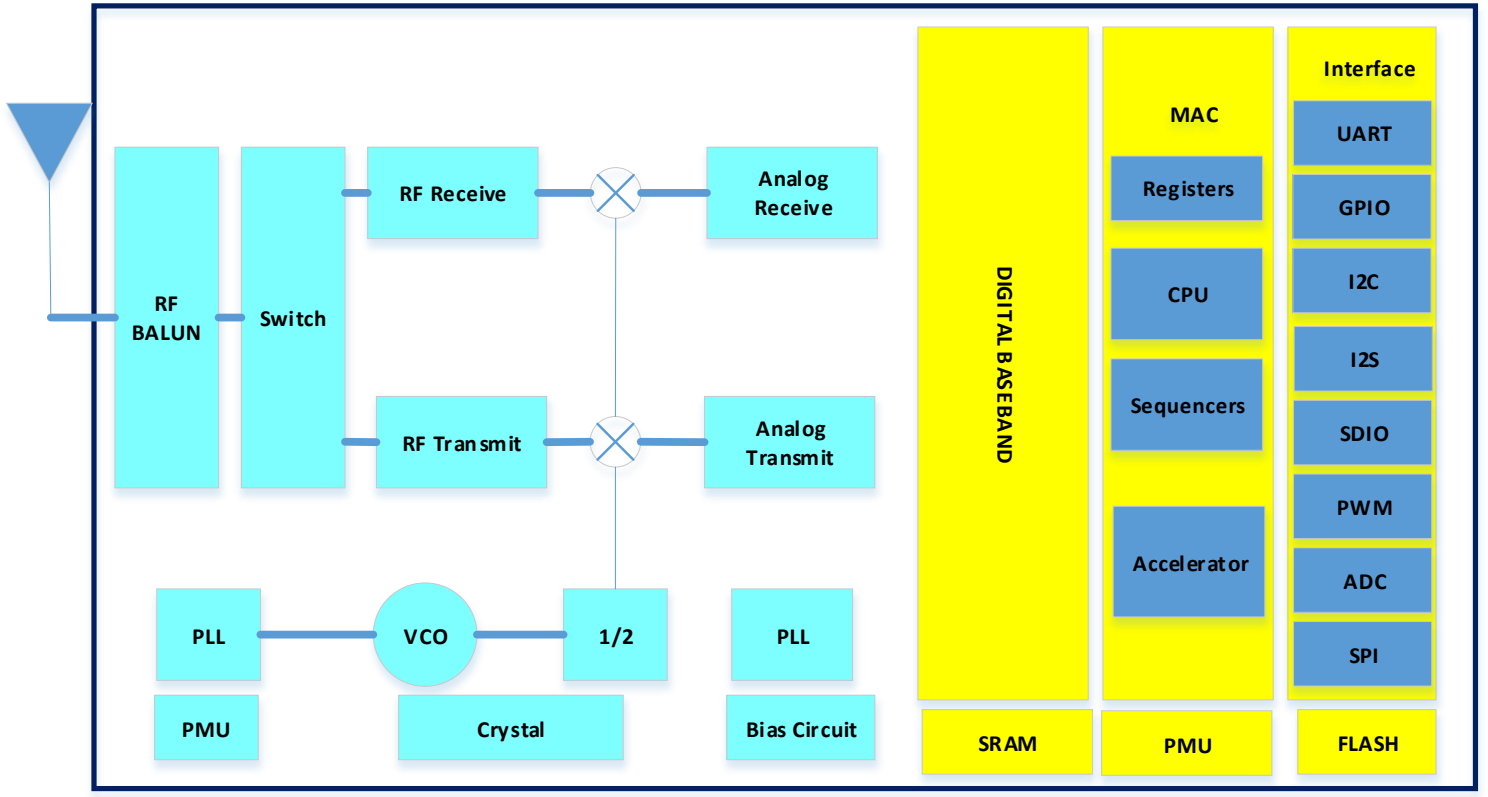

Gambar 4. Blok diagram ESP8266EX

Penggunaan ESP8266 pada penelitian ini berperan ganda yaitu dihubungkan ke perangkat sensor RFID, untuk mengolah data hasil bacaan RFID, kemudian ESP8266 juga berperan sebagai client yang akan berkomunikasi dengan server, sehingga posisi ESP8266 sangat sentral seperti terlihat pada gambar 5. 


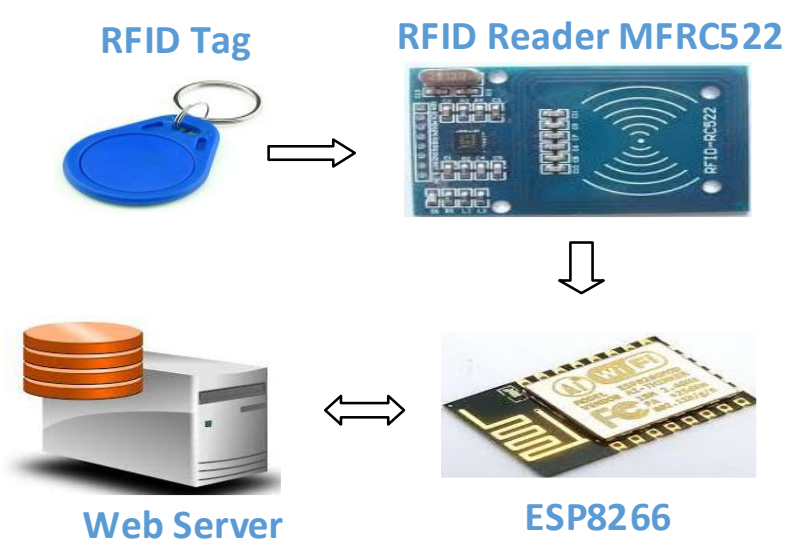

Gambar 5. Alur data melalui ESP8266

Embedded system pengamanan pintu di desain dan dirancang untuk mengintegrasikan beberapa komponen atau device menjadi satu sistem. Beberapa perangkat keras dikonfigurasikan satu sama lain yang diantaranya adalah Wirelless ESP8266, RFID Reader MFRC522, Catu daya, buzzer, dan relay. Hasil perancangannya dapat dilihat pada gambar 6 .

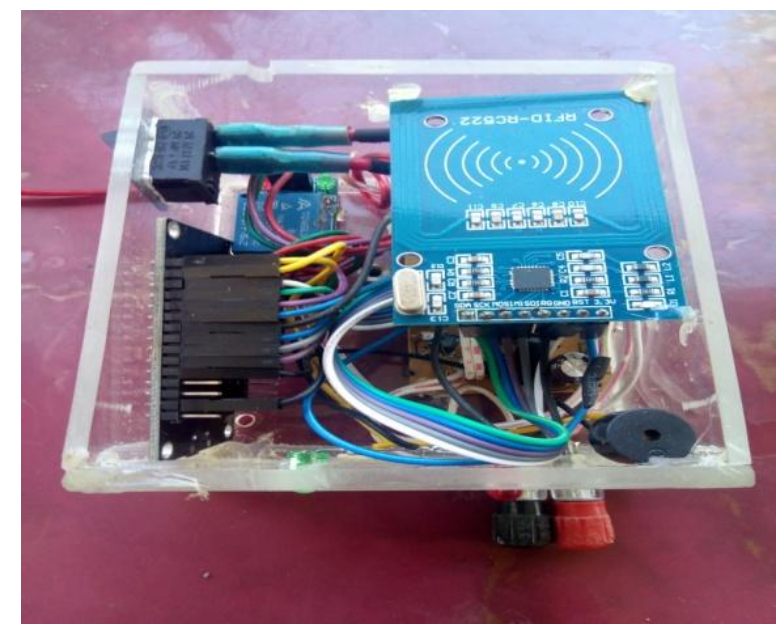

Gambar 6. Embedded System Pengamanan Pintu

Komunikasi data Sebagai media komunikasi antara sensor RFID dan perangkat lunak yang dibuat, direalisasikan dengan memanfaatkan protocol http dimana semua perangkat keras dalam hal ini RFID sensor bertindak sebagai client dan perangkat lunak yang di bangun bertindak sebagai web server dan penyimpan datadata transaksi (database), proses transaksi data pada system ini dapat dilihat pada gambar 7 . 


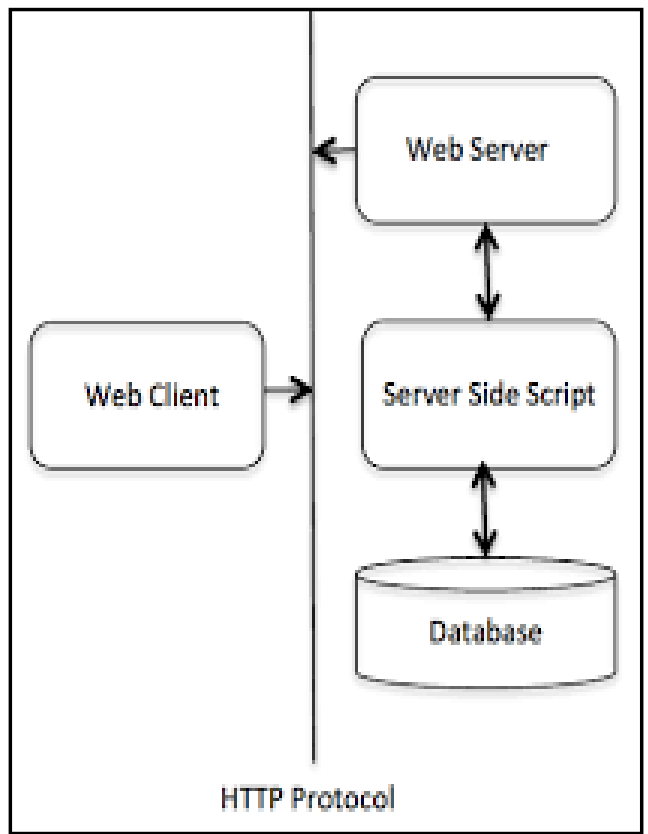

Gambar 7. Alur Data HTTP Protocol

2.2 Web server dengan menggunakan Raspberry Pi

Sebagai alternative solusi untuk web server yang akan digunakan sebagai media penyimpan data dan untuk menjalankan perangkat lunak yang dibuat, dipilih sebuah single board computer (SBC) dalam hal ini menggunakan Raspberry Pi (gambar 8). SBC ini memiliki spesifikasi yang cukup untuk bertindak sebagai server karena perangkat ini memiliki beberapa keunggulan seperti :

1. A 900MHz quad-core ARM Cortex-A7 CPU

2. 1GB RAM

3. 4 USB ports

4. 40 GPIO pins

5. Full HDMI port

6. Ethernet port

7. Combined $3.5 \mathrm{~mm}$ audio jack and composite video

8. Camera interface (CSI)

9. Display interface (DSI)

10. Micro SD card slot

11. Video Core 3D graphics core

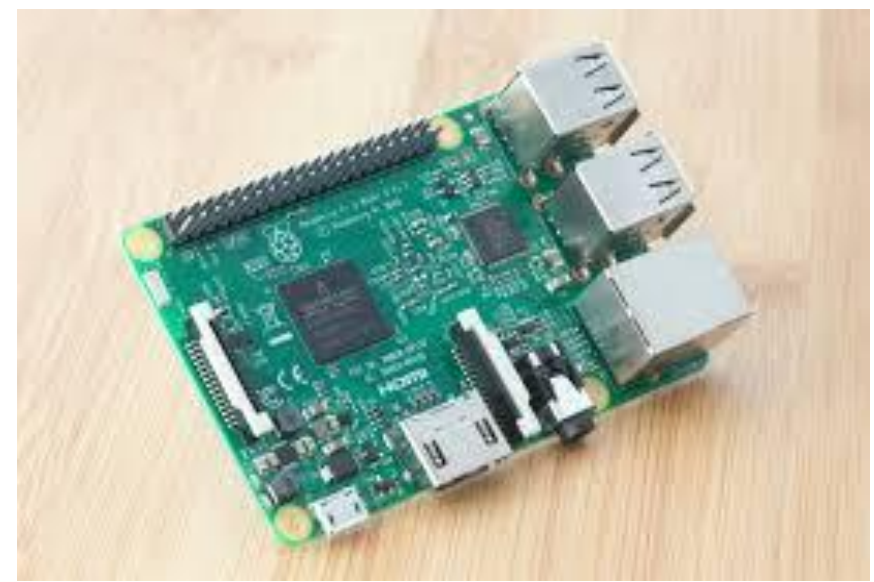

Gambar 8. Single Board Computer, Raspberry pi 
Untuk mengaktifkan semua fitur yang ada pada Raspberry ini, maka pertama-tama diinstallkan system operasi Linux raspberrypi, kemudian setelah itu diinstal Apache sebagai server dan PHP sebagai script language, serta Mysql sebagai database, sehingga raspberry ini dapat berperan sebagai web server untuk system yang dibuat. Detail versi tools yang digunakan dapat dilihat pada gambar 9 dan gambar 10.

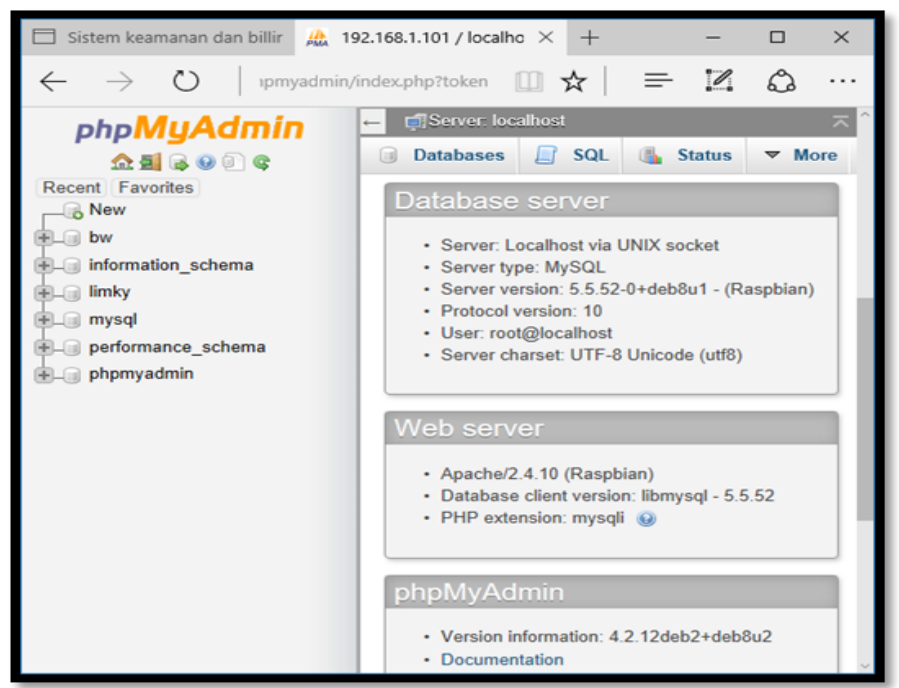

Gambar 9. Detail web server, database server, phpmyadmin yang terinstall

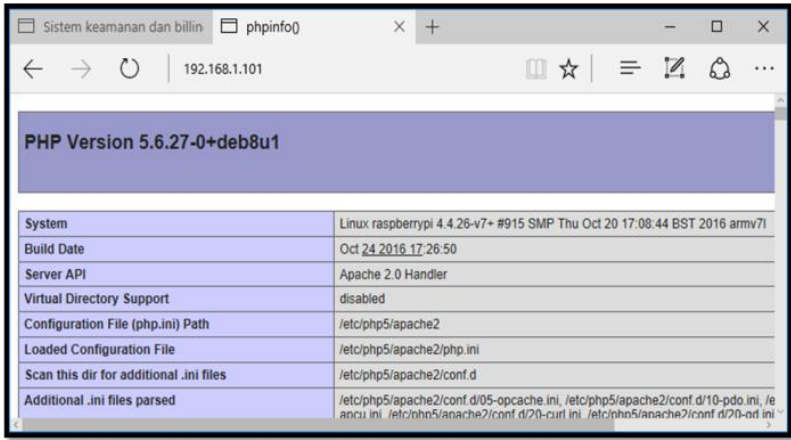

Gambar 10. Detail versi PHP yang terinstall

Karena berperan sebagai server maka pada penelitian ini alamat IP dari Raspberry ini di setting menjadi static di 192.168.1.101, sehingga semua client (sensor RFID) harus di program alamat IP servernya ke-alamat IP Raspberry ini. berikut penggalan kode untuk membuat IP raspberry menjadi static, dengan memperbaruhi file bernama : dhcpcd.conf. pada path : /etc/dhcpcd.conf
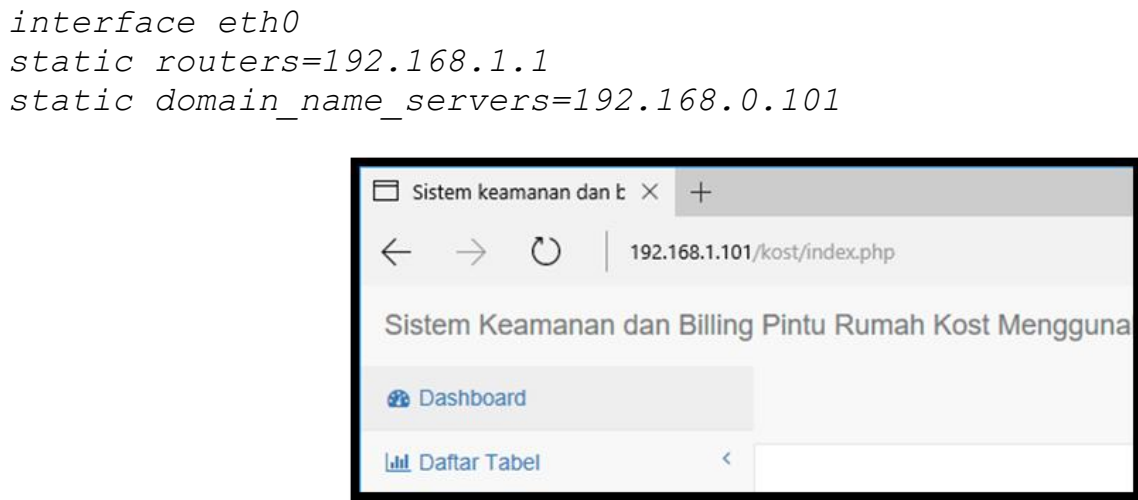

Gambar 11. IP server di set ke 192.168.1.101 
Proses migrasi server ke SBC dalam hal ini Raspberry tergolong cukup mudah, selanjutnya akan dilakukan pemanggilan/request ke server dengan menggunakan browser dari sebuah komputer untuk melihat apakah server dapat merespon dengan baik atau tidak. berikut adalah hasil-hasil akses ke web server pada SBC.

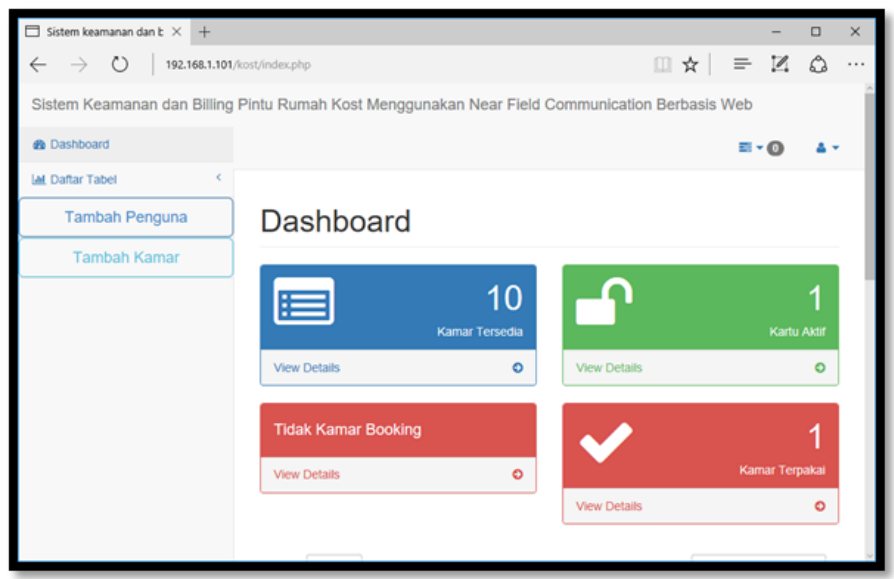

Gambar 12. Tampilan Dashboard pada server SBC

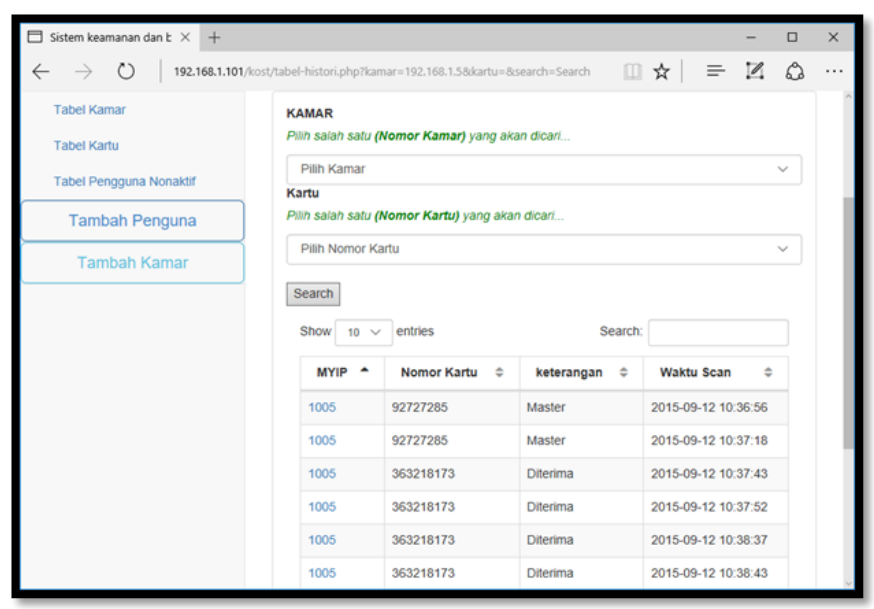

Gambar 13. Tampilan pemindaian kartu

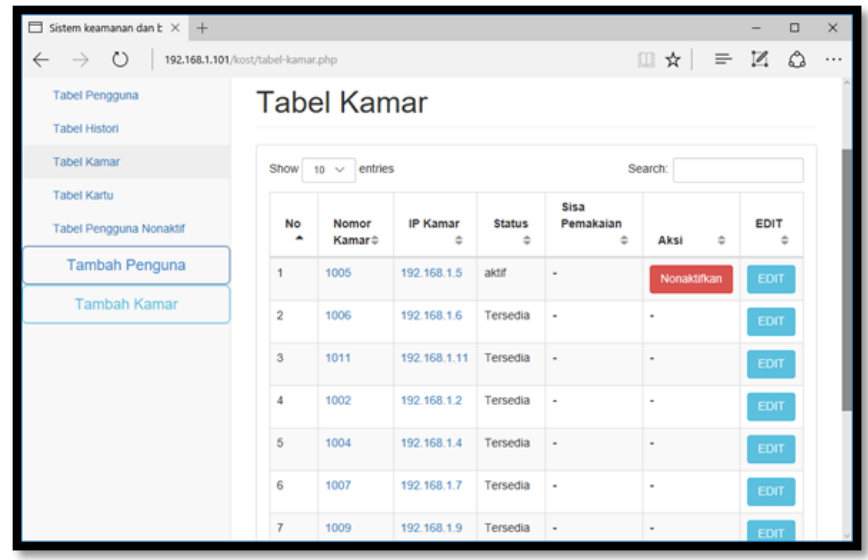

Gambar 14. Akses ke tabel kamar 


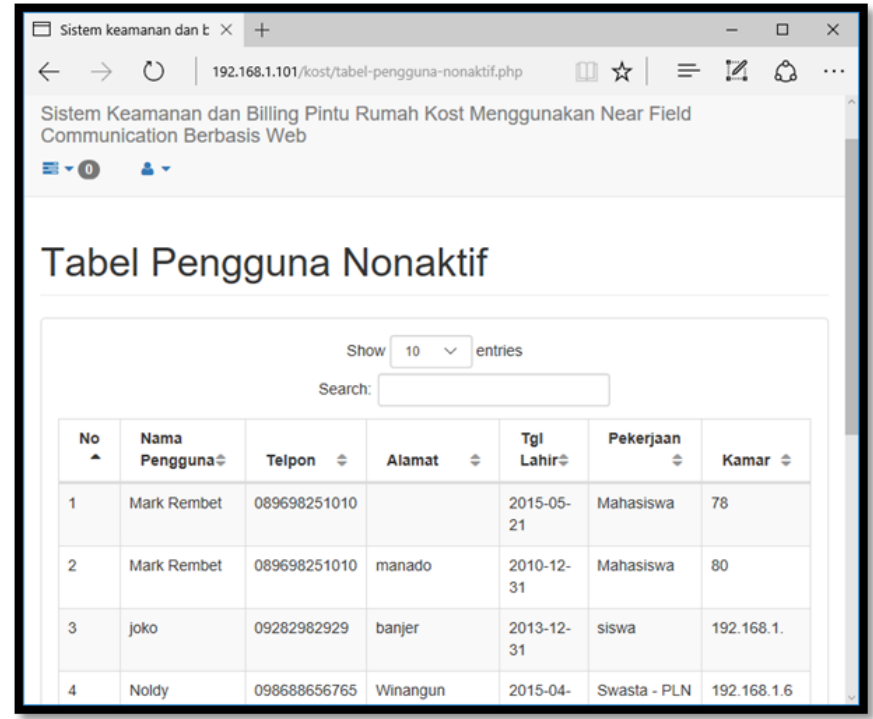

Gambar 15. Akses ke status pengguna

Dari data yang ditunjukkan oleh gambar 11 sampai dengan 15 diatas dapat dilihat bahwa penggunan Raspberry sebagai server dapat berjalan dengan baik dimana semua request dari browser dapat direspons dengan menampilkan halaman-halaman yang dimintakan. Selain itu juga telah dilakukan pengujian sistem keseluruhan dimana dicobakan pemindaian terhadap RFID sensor dengan menggunakan kartu yang telah terdaftar, dimana waktu tunggu maksimal terhadap respon yang dihasilkan oleh server untuk menyatakan user valid dan terotentifikasi, sehingga pintu dapat dibuka berada pada kisaran 2000 mili-detik. Hasil ini dirasa cukup untuk keperluan respon system pada system keamanan dan billing pintu rumah kost ini.

\section{KESIMPULAN}

Proses implementasi dengan menggunakan media komunikasi wireless ESP8266 telah diterapkan pada sistem keamanan dan billing rumah kost ini, dimana komunikasi secara wireless dapat menggantikan komunikasi dengan menggunakan kabel sehingga penggunaan kabel dapat diminimalisir. Peran SBC dalam hal ini raspberry yang digunakan sebagai sebagai webserver dapat berjalan dengan baik dimana, request dari client dapat di handle dengan waktu respon sekitar 2000 mili-detik.

Sistem ini masih perlu dikembangkan dari sisi perangkat keras dengan melakukan riset lanjutan untuk analisa kegagalan sistem, karna hal ini bisa terjadi kapan saja.

\section{PUSTAKA}

[1] Suryadiputra, L. 2010. Analisis dan Perancangan Sistem Karcis Elektronik pada Gerbang Masuk Busway dengan Menggunakan RFID, Jurnal ComTech, Vol.1 No.2., 942-955.

[2] Charles P. M. S, \& Fakhruddin R. B. 2010. Perancangan Sistem Pembayaran Biaya Parkir Secara Otomatis Menggunakan RFID (Radio Frequency Identification). Konferensi Nasional Sistem dan Informatika.

[3] Beny, N, dan dkk. 2015. Perancangan Dan Pengujian Miniatur Lift Berbasis Arduino Dengan Menggunakan Rfid Sebagai Sistem Identifikasi Lantai. SINERGI, Vol. 19, No. 3, hal. 211-216.

[4] Eko B. S, \& Bobi. K. 2015. Perancangan Sistem Absensi Kehadiran Perkuliahan dengan Menggunakan Radio Frequency Identification (RFID), Jurnal CoreIT, Vol.1, No.2.

[5] Figa. U. dkk. 2015. Prototype Sistem Keamanan Pintu Menggunakan Radio Frequency Identification (RFID) Dengan Kata Sandi Berbasis Mikrokontroler, Jurnal Coding, Vol. 3, No. 1, hal 22-31 
[6] Denny Darmawan Diredja, dkk. 2010. Perancangan Sistem Pengaman Pintu Menggunakan RFID Tag Card Dan Pin Berbasis Mikrokontroler AVR Atmega 8535, Konferensi Nasional Sistem dan Informatika.

[7] Pinrolinvic M., 2015. "Sistem pengamanan pintu jamak dengan RFID sensor berbasis web", Jurnal Elektro vol 8. no.2 page 79-86. Unika Atma Jaya, Jakarta.

[8]. Madcoms. (2010). Sistem Jaringan Komputer untuk Pemula. Yogyakarta :Andi.

[9]. Aryanto, Mahmud. (2010). Ip Camera Dan Aplikasinya. Jakarta : Elex Media Komputindo.

[10]. Yuwono, R. (2014). Design of Circular Patch Microstrip Antenna with Egg Slot for 2.4 GHz UltraWideband Radio Frequency Identification (UWB RFID) Tag Applications. Jurnal Internasional Applied Mechanics and MaterialsVol. 513-517.

[11]. Maryono. 2005. Dasar-dasar Radio Frequency Identification (RFID) Teknologi Yang Berpengaruh di Perpustakan. Media Informasi. Vol. XIV No.20.

[12]. Doni S. dkk. 2010. Sistem Otomasi Perpustakaan Dengan Menggunakan Radio Frequency Identification (RFID). Jurnal Informatika Mulawarman. Vol. 5. No. 3.

[13]. Datasheet MFRC522, (online), (https://www.elecrow.com/download/MFRC522\%20Datasheet.pdf, diakses 22 mei 2007). 